\title{
Pioderma gangrenoso em mastoplastia e abdominoplastia
}

\section{Pyoderma gangrenosum in mammaplasty and abdominoplasty}

Trabalho realizado no Hospital Quinta Dor, Rio de Janeiro, RJ, Brasil.

Artigo submetido no SGP (Sistema de Gestão de Publicações) da RBCP.

Artigo recebido: 16/9/2009 Artigo aceito: 16/9/2010

\begin{abstract}
RESUMO
Pioderma gangrenoso é uma doença rara de causa desconhecida, inflamatória, ulcerativa e dolorosa, com formação de bolhas e pústulas, tipo autoimune e não infecciosa. É caracterizado inicialmente por uma lesão cutânea avermelhada de caráter inflamatório do tipo rash cutâneo, que evolui para necrose de pele. Pode representar uma primeira resposta imunológica na pele durante o ato operatório, semelhante à doença de Crohn, doença de Behçet, doenças autoimunes, leucemias, artrites, ou mesmo ainda qualquer outro pequeno trauma ocorrido na pele em data anterior à cirurgia. Não se sabe a origem do processo que deu a esta reação imunológica.
\end{abstract}

Descritores: Pioderma gangrenoso. Doenças auto-imunes. Mamoplastia/efeitos adversos. Abdome/cirurgia/ efeitos adversos.

\section{ABSTRACT}

Pyoderm gangrenosum is an unknown skin inflammatory and ulcerative non infected disease, painful that starts with vesicles formation like cutaneous rash that develop to skin necrosis. It may represent the first immunologic skin reaction during the surgery, similar to Crohn disease, Behçet disease, autoimmune diseases, leukemia, arthritis or even any type of small skin trauma days before the surgery. The immunologic reactions are still unknown.

Keywords: Pyoderma gangrenosum. Autoimmune diseases. Mammaplasty/adverse effects. Abdomen/surgery/adverse effects.

\section{INTRODUÇÃO}

Pioderma gangrenoso foi descrito pela primeira vez em 1930 , tendo sido utilizado o termo abscesso neutrofílico estéril, pelo fato das lesões cutâneas não conterem microorganismos patogênicos. As infecções que advêm são por contaminação secundária, de maneira a confundir o diagnóstico e tratamento ${ }^{1-12}$.

A reação imunológica determina a dilatação capilar e consequente rash cutâneo. Inicia-se com uma reação em cadeia, com intensa migração de neutrófilos para o local da reação, localizado na camada basal da pele, seguida de grande produção de colagenase. Esta enzima destrói o colágeno e a rede capilar que nutre pele e a camada basal. Com as ligações rompidas a pele se desfaz e a necrose se inicia. Na presença de tecido necrosado, o organismo aumenta no local a quantidade de neutrófilos e macrófagos, para digerir e completar a limpeza da ferida. Os neutrófilos em maior quantidade produzem mais colagenase, que destrói mais tecido cutâneo, refazendo e perpetuando o ciclo. A atrofia da pele determina uma fina camada epitelial queratinizada que forma "bolha" contendo restos digeridos e liquefeitos do derma profundo, de coloração azul escuro ou violácea. A bolha rapidamente se rompe e as enzimas se espalham pela ferida, continuando o processo digestor e formando uma ulceração. Esta reação por contiguidade afeta a pele normal circunvizinha, que provoca o rash cutâneo e novamente o ciclo de destruição se repete indefinidamente.

Atualmente, os dermatologistas discutem sobre a denominação pioderma gangrenoso para redefinir como autofagenismo, isto é, uma doença autoimune que se autoalimenta e destrói.

\section{RELATO DO CASO}

Paciente caucasiana, de 34 anos de idade, submetida a mastoplastia de redução e pexia associada a abdominoplastia 
tipo incisão pubiana transversal baixa e lipoaspiração num único tempo operatório (Figura 1). A paciente recebeu alta hospitalar no segundo dia de pós-operatório, assintomática, sob antibioticoterapia e em boas condições clínicas.

No $6^{\circ}$ dia de pós-operatório, a paciente apresentou febre de $39,6^{\circ}$ Celsius. O hemograma revelou discreta leucocitose, proteína $\mathrm{C}$ reativa ligeiramente aumentada, entretanto a radiografia de tórax e os exames de urina encontram-se dentro dos limites da normalidade.

No $7^{\circ}$ dia de pós-operatório, a febre continuava a oscilar com o uso de dipirona, as mamas e o abdome não apresentavam sinais de qualquer anormalidade, exceto duas pequenas lesões cutâneas bolhosas de cor violácea de $0,5 \mathrm{~cm}$ de diâmetro cada uma na região inferior do umbigo. Com dez horas estas bolhas evoluíram para necrose e destruição total da pele, com drenagem purulenta abundante num diâmetro de $5 \mathrm{~cm}$ e profundidade atingindo toda a espessura da pele até a fáscia muscular subjacente.

No $8^{\circ}$ dia de pós-operatório, surgiu um rash cutâneo ao longo da cicatriz vertical e do complexo aréolo-papilar com evolução similar as do umbigo, sob a forma de bolhas escuras, ulceração e necrose de pele em ambas as mamas (Figura 2). Aspectos similares apareceram isoladamente ao longo da cicatriz do abdome.

A bacterioscopia e a cultura nada revelaram. Além da intensa sensação dolorosa equivalente a queimadura de

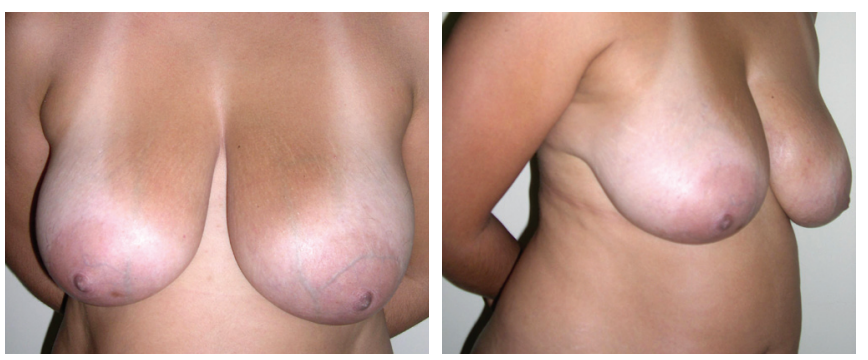

Figura 1 - Pré-operatório.
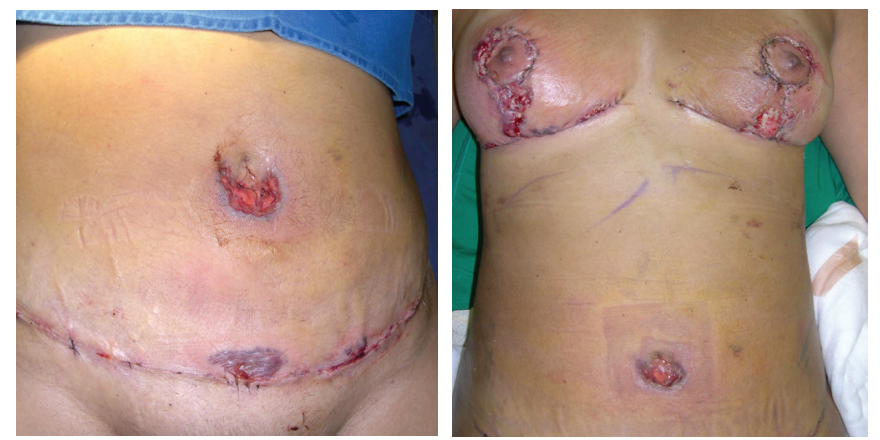

Figura 2 - No 8 dia de pós-operatório, surgiu um rash cutâneo ao longo da cicatriz vertical e do complexo aréolo-papilar com evolução similar as do umbigo, sob a forma de bolhas escuras, ulceração e necrose de pele em ambas as mamas.
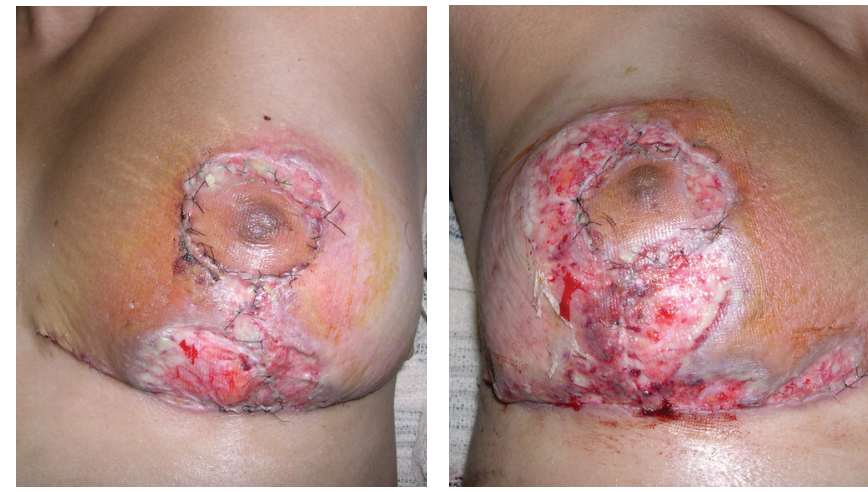

Figura 3 - Progressão da lesão cutânea nas mamas.
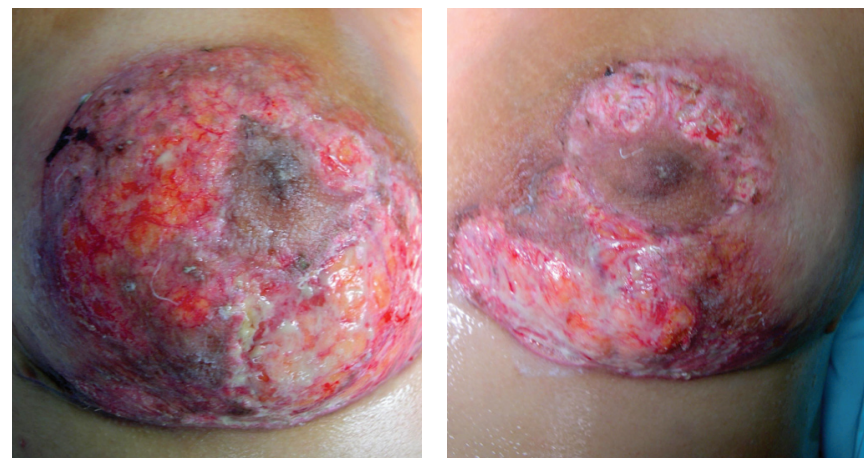

Figura 4 - Grande extensão da superfície mamária destruída no $12^{\circ}$ dia de pós-operatório.

segundo e terceiro grau, a destruição cutânea foi progressiva de 1 a $2 \mathrm{~cm} /$ dia (Figura 3 ).

No $12^{\circ}$ dia de pós-operatório, a extensão da superfície destruída havia atingido de 140 a $190 \mathrm{~cm}^{2}$, equivalente a 2/3 de cada superfície mamária (Figura 4). As imagens da tomografia computadorizada demonstraram integridade absoluta do parênquima mamário e o seu invólucro cutâneo com os pontos de sutura preservados.

O tratamento compreendeu limpeza local, sem debridamento das bordas das feridas, com creme tópico de betametasona e neomicina, creme de óxido de zinco a $10 \%$ e nutraplus, além de creme de ureia a $8 \%$. O tratamento sistêmico foi de prednisolona injetável de $1 \mathrm{mg} / \mathrm{kg}$ de peso, num total de 60 mg por dia, e Clavulin, $3 \mathrm{~g}$ ao dia.

$\mathrm{Na}$ região do hipogástrio, formou-se um grande edema e endurecimento com esteatose e reação inflamatória que estendia do orifício de drenagem da região umbilical até a cicatriz cirúrgica da abdominoplastia, com lavagem diária deste túnel com soro fisiológico.

A cicatrização por segunda intenção das mamas e da ferida umbilical se processou centripetamente. A cicatriz final no umbigo mimetizou o seu aspecto natural, enquanto nas mamas ocorreu um resultado estético desfavorável face à intensa destruição cutânea, semelhante às por segunda 


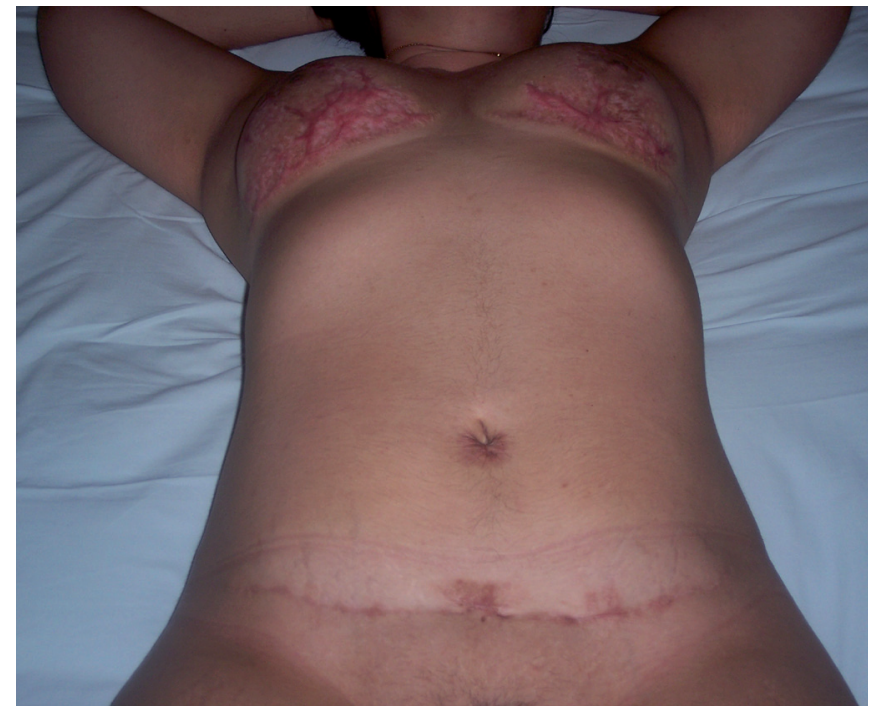

Figura 5-Pós-operatório: depois de seis meses.

intenção, com áreas de cicatrizes hipertróficas.

No terceiro mês de evolução, surgiram alguns pequenos cistos identificados como lesões cutâneas tipo mília, formados por restos epiteliais que foram eliminados.

No quarto mês de pós-operatório, não foram mais aplicadas medicações sistêmicas, havendo cicatrização completa das lesões mamárias durante o sexto mês. Foi surpreendente a agressividade da doença, o grande volume de secreção purulenta e a necrose rápida da pele.

A Figura 5 demonstra o aspecto pós-operatório de 6 meses.

\section{DISCUSSÃO}

Durante sua evolução, o paciente não respondeu à terapia sistêmica dos antibióticos de última geração, pela ausência de micro-organismos patogênicos.

Em nenhum momento as feridas foram debridadas nos seus limites, por sabermos que a progressão da destruição cutânea estaria a partir dos limites da área ressecada.

Produtos que tivessem colagenase na sua composição não foram aplicados, para evitar o adicionamento de mais enzima digestora à ferida. Finalmente, a opção de enxertia cutânea foi descartada, pela possibilidade de detonar o mesmo processo ao ser realizado o trauma na área doadora dos enxertos.

Aproximadamente $50 \%$ dos pacientes que apresentam esta doença têm doenças sistêmicas como artrite reumatoide, leucemia, anemia, doenças inflamatórias crônicas do aparelho urinário, pênfigo, psoríase, doença de Crohn, piodermite de Sweet ou lúpus. É ainda importante fazer diagnóstico diferencial da doença de Behçet, Stafiococcia, Streptococia, fasciite necrotizante, Mycobacteria, úlceras herpéticas, etc.

Quanto ao prognóstico, muitos pacientes desenvolvem um simples episódio da doença, que é resolvido com curta terapia e nunca mais apresentam esta reação autoimune, particularmente aos que não têm doenças associadas. Há relato de caso publicado que reporta o aparecimento da doença, por duas vezes, no mesmo paciente, após traumas cutâneos em épocas e locais diferentes do corpo.

\section{REFERÊNCIAS}

1 Brunsting LA, Goeckermann WH, O'Leary PA. Pyoderma (echthyma) gangrenosum clinical and experimental observations in five cases occurring in adults. Arch Dermatol Syphilol. 1930;22:655-80.

2. Clugston PA, Thompson RP, Schlappner OL. Pyoderma gangrenosum after reduction mammoplasty. Can J Surg 1991;34(2):157-61.

3. Gudi VS, Julian C, Bowers PW. Pyoderma gangrenosum complicating bilateral mammaplasty. Br Plast Surg. 2000;53(5):440-1.

4. Gulyas K, Kimble FW. Atypical pyoderma gangrenosum after breast surgery. Aesthetic Plast Surg. 2003;27(4):328-31.

5. Jain A, Nanchahal J, Bunker C. Pyoderma gangrenosum occurring in a lower limb fasciocutaneous flap: a lesson to learn. Br J Plast Surg. 2000;53(5):437-40.

6. Callen JP, Jackson JM. Pyoderma gangrenosum: an update. Rheum Dis Clin North Am. 2007;33(4):787-802.

7. Alese OB, Irabor DO. Pyoderma gangrenosum and ulcerative colitis in the tropics. Rev Soc Bras Med Trop. 2008;41(6)664-7.

8. Levy S. Sobre o uso de câmara hiperbárica em pyoderma gangrenosum da mama após mastoplastia redutora. Comunicação pessoal; 2009.

9. Resano M. Pyoderma gangrenosum: uso de pele artificial íntegra para cobertura da ferida do pyoderma gangrenosum em complicação de mastoplastia redutora. Comunicação pessoal; 2009.

10. Bonamigo RR, Behar PR, Beller C, Bonfá R. Pyoderma gangrenosum after silicone prosthesis implante in the breasts and facial plastic surgery. Int J Dermatol. 2008;47(3):289-91.

11. Jaimovich CA. Sobre o uso de prednisona tópica na ferida do pioderma gangrenoso. Comunicação pessoal; 2009.

12. Santana K. Sobre a preservação areolar da mama no pyoderma gangrenoso. Comunicação pessoal; 2009. 